\title{
The effect of mentholated cigarette use on interleukin-6 responses across different HIV positive race/ethnic subgroups
}

This article was published in the following Dove Press journal:

International Journal of Interferon, Cytokine and Mediator Research

9 November 2010

Number of times this article has been viewed

María José Míguez-Burbano ${ }^{1,2}$

Rhonda Rosenberg ${ }^{2}$

Robert Malow ${ }^{2}$

Ximena Burbano ${ }^{4}$

Jessy Devieux ${ }^{2}$

Nair Madhavan ${ }^{3}$

'Institute of Neuroimmune

Pharmacology, Florida International

University College of Medicine,

Miami, FL, USA; ${ }^{2}$ Department of

Health Promotion and Disease

Prevention, Robert Stempel College

of Public Health and Social Work and

College of Medicine, ${ }^{3}$ Department

of Immunology, College of Medicine,

Florida International University

Miami, FL, USA; ${ }^{4}$ Zilonis Health Care

Research, Miami, FL, USA
Correspondence: María José Míguez-Burbano Institute of Neuroimmune Pharmacology, College of Medicine and Department of Health Promotion and Disease Prevention, Robert Stempel

College of Public Health and Social Work, Florida International University, Miami, FL, USA

Email mjmiguezII63@bellsouth.net

\begin{abstract}
In this report, we analyze trends in interleukin-6 (IL-6) production in people living with human immunodeficiency virus (PLWH), as a function of smoking behaviors and race, using a clinic-based case-control design. Peripheral blood mononuclear cells (PBMCs) were collected from a multiethnic cohort of 120 PLWH to measure IL-6 in culture supernatant. The data indicated that stimulated PBMC produced significantly higher levels of IL-6 in smokers than nonsmokers. However, as expected, this relationship was substantially modified by race. The distinctive production of IL-6 across different racial groups highlights the need for additional studies and suggests that African American smokers have enhanced production of IL-6 than other groups. Additional analyses indicate that higher IL-6 levels are related to the predicted use of mentholated cigarettes, which are more frequently used by African Americans. These findings warrant further investigation and indicate the critical need for tailored preventive interventions.
\end{abstract}

Keywords: AIDS, interleukins, smoking, race/ethnicity, menthol cigarettes

\section{Introduction}

Similar to other inflammatory and immunological diseases implicated in premature mortality, human immunodeficiency virus (HIV) has had distinctive impacts across various racial/ethnic groups. Proinflammatory markers, particularly interleukin-6 (IL-6), have been recently linked to an increased risk of all causes of mortality in models adjusted for well-known confounding variables. ${ }^{1-3}$ Levels of IL-6 are likely to be influenced by several behavioral and genetic factors. ${ }^{1-11}$ Associations between common gene variations in IL- 6 and race/ethnicity have been examined in several studies but with inconsistent findings, and these studies did not focus on people living with HIV (PLWH). ${ }^{46}$ Saijo et al ${ }^{7}$ studied 347 Japanese individuals; Friedlander et $\mathrm{l}^{8}$ studied 475 Israeli families; and the AIRGENE study targeted Europeans with myocardial infarct. ${ }^{7-10}$

Also, potential factors associated with IL-6 elevations have been analyzed by Neuhaus et $\mathrm{a}^{11}$ using three large US cohorts of people with and without HIV. However, these analyses failed to assess the collective contribution of tobacco and smoking use behaviors (ie, menthol use) or examine how race/ethnicity may have shaped their findings. ${ }^{11}$ Compared with Caucasians, African Americans and Hispanics tend to smoke mentholated cigarettes. It has been argued and debated that the increased nicotine, tar, carbon monoxide, and various carcinogenetic compounds in menthol brands could result in increased medical problems. ${ }^{12-16}$ Specifically, tar and carbon monoxide have been linked with an increased proinflammatory response including IL-6. ${ }^{17}$ Further, this 
national study used either stored serum or plasma, which are problematic for measuring cytokine levels, that depend on clearance for accurate assessment. A preferred method is to assess cytokine production in culture supernatants of peripheral blood mononuclear cells (PBMC) collected at the same time of day to obtain the most accurate comparison across individuals.

Additional evidence also prompts our interest. Vast epidemiological evidence indicates that meager health and higher mortality in the general population are associated with smoking status. Moreover, compared with the general population, PLWH are at high risk of developing malignancies and cardiovascular and kidney diseases, which are related to smoking. ${ }^{18-20}$ In this study, in order to add clarity to this area of research, we have attempted to more comprehensively assess the relationships between IL- 6 and smoking behaviors by race in PLWH, while controlling for well-known confounding factors.

\section{Subjects and methods Sampling}

Participants included 120 men and women regularly treated at the Jackson Memorial Medical Center, Miami, Florida. They were consecutively enrolled in the study upon informed consent and meeting the following inclusion criteria: aged at least 18 years and confirmed to be infected only with HIV-1 virus. We chose a study population from an open-access public health system with standard treatment protocols to minimize possible confounds of results due to lack of treatment, unequal medical care, and other such factors related to social inequalities. Participants were enrolled regardless of clinical (ie, symptomatic, asymptomatic, and AIDS) and treatment status (ie, highly active antiretroviral treatment [HAART] yes/no). Nevertheless, the distribution of participants across Centers of Disease Control and Prevention (CDC) categories was well balanced with almost half (48\%) having AIDS and $60 \%$ of the group receiving HAART.

Nonambulatory patients and those with serious comorbidities that might affect outcome, such as central nervous system opportunistic infection, head injury, tumors, major psychiatric disease, developmental disorders, cirrhosis, severe malnutrition, or confirmed cardiovascular disease at baseline, were excluded. Also, excluded were those with a history of any immune-based disease (ie, malignancies, autoimmune diseases, arthritis, and viral hepatitis) to further minimize the possibility that IL-6 was altered by other diseases. Moreover, we excluded febrile patients or those with acute illness (ie, cold and respiratory infections) as it may alter cytokine production. To also reduce confounding due to illicit drugs and viral hepatitis, exclusion criteria included liver enzymes with 2 standard deviations above normal values, injection, and/or daily drug use at the time of enrollment. Those willing to participate (98\%), who provided written informed consent, were enrolled and followed for 6 months.

A baseline assessment included standardized research questionnaires on tobacco, alcohol, and drug use supplemented by a past and present medical history, physical examination, and laboratory testing. Our definition of HAART for analytical purposes was guided by the published recommendations of the Panel on Antiretroviral Guidelines for Adults and Adolescents of 2008. ${ }^{21}$

\section{Tobacco exposure}

Information on tobacco use (cigarettes, cigars, and pipes) included duration of tobacco use (years), the estimated number of cigarettes, cigars, and/or pipes per day, the age at which smoking began, cigarette brand, and details regarding filter and mentholated cigarette use.

Participants were categorized as nontobacco users (ie, never smoked) and current tobacco users (ie, reported present, regular cigarette smoking). Tobacco use was quantified as follows: $0=$ never, $1=$ once/last 30 days, $2=$ once/week, $3=3-4$ times per week, 4 = daily. As per World Health Organization recommendations (WHO), heavy smoker was defined as a smoker with a daily consumption of more than 20 cigarettes. To quantify cumulative lifetime use, current smokers were asked at what age they began smoking, and ex-smokers were asked at what age they started and quit smoking. Number of years of smoking was calculated as follows: for smokers, current age minus age at which participant began smoking, and for ex-smokers, age at which participant quit smoking minus age at which participant began smoking.

\section{Interleukin-6}

Sterile, heparinized vacutainer tubes were used to collect blood samples, kept at room temperature after collection, and transported to the laboratory for culture within 4 hours.

\section{Stimulants}

To test their capacity to secrete IL-6, PBMCs $10^{5} / \mathrm{mL}$ were stimulated with $10 \mu \mathrm{g} / \mathrm{mL}$ plate-bound anti-CD3 mAb plus $1 \mu \mathrm{g} / \mathrm{mL}$ soluble anti-CD28 mAb for 24 hours. We used $10 \mu \mathrm{L} /$ well for a final concentration of $5 \mu \mathrm{g} / \mathrm{mL}$ in Royal Park Memorial Institute medium 1640 with L-glutamine (Gibco BRL ${ }^{\circledR}$, Gaithersburg, MD), penicillin, and streptomycin. 


\section{Procedure}

Each well of a 24-well plate was added with $100 \mu \mathrm{L}$ of blood; $900 \mu \mathrm{L}$ medium with antibiotics; and with or without anti-CD3 was added to each well. A 48 hours, plates were removed from the incubator and centrifuged, and $800 \mu \mathrm{L}$ of supernatant fluid was collected from each well and frozen at $-70^{\circ} \mathrm{C}$.

\section{Controls}

A control well (growth medium without stimulant) was included for each blood sample.

\section{Calculations}

Levels of IL-6 in the culture supernatant fluids were measured by commercial enzyme-linked immunosorbent assays (Beckman/Coulter Corporation, Miami, FL) in which standard curves using recombinant cytokines were generated. These assays were appropriately quality controlled with different known sources of recombinant and natural cytokines (including National Institute for Biological Standards and Control/WHO reference standards) and throughout different patient categories. The number of lymphocytes in each assay was obtained from the complete blood count, and levels of cytokines in supernatant fluids were normalized to $1,00,000$ lymphocytes $\left(10^{5}\right)$.

\section{Virological and immunological assessments}

To determine immune status and HAART effectiveness, CD4 and CD8 lymphocyte subsets were determined by flow cytometry as per National Institute of Allergy and Infectious Diseases laboratory protocols. HIV viral loads were obtained by polymerase chain reaction $\left(\mathrm{COBAS}^{\circledR}\right.$ Amplicor Analyzer; Roche Molecular Diagnostics, Pleasanton, CA). The definition of HAART used for analyses was guided by the published recommendations of the Panel on Antiretroviral Guidelines for Adults and Adolescents of 2008. ${ }^{21}$

\section{Race/ethnicity}

Data on race/ethnicity were categorized in accord with the 1997 Office of Management and Budget Directive 15. We used the following mutually exclusive categories and participant self-reports to categorize them as Caucasian (white non-Hispanic), African American, and Hispanics (whites). Participants from other racial ethnic groups were excluded from the analyses because of being insufficient numbers to produce meaningful results.

\section{Other risk factors}

To investigate risk factors associated with increased levels of IL-6, potentially confounding variables, such as, age, gender, smoking, or drug use, were assessed. Drug use habits were assessed using standardized questionnaires. Considering that malnutrition, a feature observed in PLWH and in alcohol abusers, could affect IL-6 production, nutritional status was assessed using albumin and anthropometrics. Weight was measured to the nearest $0.1 \mathrm{~kg}$ on a balance beam scale, with the participant dressed in indoor clothing without shoes. Height was measured to the nearest $0.1 \mathrm{~cm}$ using a wallmounted stadiometer. Body mass index (BMI) was calculated as weight in kilograms divided by height in meters squared. Additionally, a detailed current and past medical history was obtained on each participant. Each variable was first analyzed as a continuous variable and then, dichotomized to facilitate analyses.

Alcohol consumption assessments included widely used standardized and validated brief screening questionnaires. The WHO's Alcohol Use Disorders Identification Test has three alcohol consumption questions, three drinking behavior and dependence questions, and four questions on the consequences or problems related to drinking. ${ }^{22}$ The Alcohol Dependence Scale is a widely used research and clinical tool that quantitatively measures alcohol-dependence severity. ${ }^{23}$ Its 25 items cover alcohol withdrawal symptoms, impaired control over drinking, awareness of a compulsion to drink, increased tolerance to alcohol, and salience of drink-seeking behavior. Based on criteria established by National Institute on Alcohol Abuse and Alcoholism and American Association guidelines, men who reported more than 14 drinks per week and women who reported more than 7 drinks per week were classified as hazardous drinkers, whereas those reporting fewer drinks were classified as nonhazardous drinkers. ${ }^{24}$

\section{Statistical analyses}

Data were analyzed using SAS (v. 8.1; SAS Institute, Cary, NC) and SPSS (v. 17; SPSS, Inc., Chicago, IL) software. Associations between the salient variables were examined with Pearson's correlation coefficient analyses. IL-6 (pg/10 Lym) differences between Hispanics, Caucasians, and African Americans were compared using analysis of variance after logarithmic $(\log )$ transformation.

Multivariate regression analysis was used to describe the associations between IL-6 elevations with race and smoking behaviors, although controlling for all variables that were statistically significant in the univariate analyses. Multiple logistic regression analyses were used to evaluate the effects 
of race/ethnicity, tobacco, and other potential risk factors on IL-6 levels. The initial model was constructed with age, socioeconomic status, BMI, CD4 cell counts, gender, viral loads, illicit drugs, alcohol, and HAART as predictive variables. These factors were selected because either they were recognized risk factors or they were significant $(P=0.05)$ in the univariate analysis. Nonsignificant variables $(P=0.05)$ were excluded, beginning with the least significant variables, until the final full model was determined. For this analysis, we used IL-6 quantiles rather than a convenient value. Using quantiles is particularly helpful when there are no clear clinical cut-offs available. Moreover, it avoids a direct assumption that there is a linear relationship between selected variables and IL-6. Regression output was reported as adjusted odds ratio (OR), accompanied by $95 \%$ confidence intervals (CI).

\section{Results}

\section{Sociodemographic characteristics}

With an overall $98 \%$ participation rate, 120 participants with complete data were included in the analyses. Table 1 shows baseline sociodemographics and clinical characteristics of the study population. Consistent with the matching strategy, the smoking and nonsmoking groups were very similar with the exception of racial/ethnic distribution. Table 2 shows these parameters by racial/ethnic groups.

\section{IL-6 by clinical stage and HAART}

Induction of IL-6 by PBMC after stimulation varied from 8 to 24,293 levels in picograms (pg/10 5 Lym). The Pearson coefficients for their correlations with $\log$ viral load were 0.23 ( $P<0.05)$. IL-6 and CD4 counts were moderately intercorrelated (Pearson correlation coefficient: 0.30 ;

Table I Sociodemographics according to smoking status

\begin{tabular}{llll}
\hline Variable & $\begin{array}{l}\text { Smokers } \\
\mathbf{N = 9 0}\end{array}$ & $\begin{array}{l}\text { Non-smokers } \\
\mathbf{N = 3 0}\end{array}$ & $\mathbf{P}$ value \\
\hline Age & $44.5 \pm 10$ & $42 \pm 9.7$ & NS \\
Men & $65 \%$ & $61 \%$ & NS \\
Women & $35 \%$ & $39 \%$ & \\
Black & $37 \%$ & $25 \%$ & 0.06 \\
Hispanic & $56 \%$ & $65 \%$ & \\
White & $7 \%$ & $10 \%$ & \\
Income $<\$ 20,000$ & $89 \%$ & $87 \%$ & NS \\
HAART & $21 \%$ & $19 \%$ & - \\
Albumin & $4.0 \pm 0.2$ & $4.0 \pm 0.5$ & NS \\
Hazardous alcohol use & $40 \%$ & $27 \%$ & NS \\
\hline
\end{tabular}

Notes: Values are mean \pm standard deviation or percentages. The data represent descriptive statistics and comparisons of baseline key variables between smokers and non-smokers. Subgroups only tended to be dissimilar in race/ethnicity. Abbreviations: NS, nonsignificant; HAART, highly active antiretroviral treatment.
$P<0.01)$. To further assess the impact of disease status on IL-6 production, participants were dichotomized as those with more or less CD4 counts of 200 cells $/ \mathrm{mm}^{3}$ and as using or not using HAART. We observed increased IL-6 production in stimulated PBMC in those with more than 200 CD4 cell counts, with a loss of upregulation in individuals with AIDS $(3.7 \pm 0.57$ vs $2.8 \pm 1.35 \log , P=0.01)$. IL-6 values differed between treated and nontreated individuals, with HAART recipients having significantly higher IL-6 values ( $3.6 \pm 0.68$ vs $2.8 \pm 1.5 \log , P=0.001$ ). Thus, it is probable that IL-6 is regulated differently with respect to HAART and disease state.

\section{IL-6 and cigarette smoking}

Ninety-three percent of the tobacco users were daily smokers (95\% CI: 89.8-95.7), 10\% of the participants were heavy smokers (smoked more than 20 cigarettes/d), 19\% were moderate smokers (10-19 cigarettes/d), and more than half (71\%) were light smokers (less than 10 cigarettes/d). We assessed trends in smoking prevalence by two measures of socioeconomic status - level of education and occupational class - within race, but no significant effects were evident.

As Figure 1 displays, Caucasians showed the highest smoking rate (67\%), followed by Hispanics (40\%), and African Americans (31\%). These rates are strikingly higher than those observed among the general population being seen at Jackson Memorial Medical Center (Caucasian 18\%, African American 14\%, and Hispanic 17\%). Most African Americans (80\%) and $20 \%$ of Hispanics, but only 1 HIV infected white, reported using mentholated cigarettes, which reflects national distribution patterns of smoking behavior. Daily consumption of cigarettes ranged from 1.8 \pm 1.3 for whites to $8.0 \pm 1.8$ for African Americans, and to $8.5 \pm 1.2$ for Hispanics. There were significant differences in the number of years of smoking between African American (18.8 \pm 2.1 years), Hispanic (16.1 \pm 3 years), and Caucasian subjects $(7.1 \pm 3.9$ years, $P=0.04)$.

The most interesting finding appears when menthol and race/ethnicity are considered together; please note that Caucasians have been excluded in this analysis because of their limited numbers. African American menthol users were 3 times more likely to be in the heavy use category of cigarette consumption than Hispanic participants $(95 \% \mathrm{CI}$ : 1.0-14.5, $P=0.04)$. Similarly, Hispanics have higher rates of smoking when their brand of choice contains menthol $(9.3 \pm 0.6$ cigarettes/d). Furthermore, compared with Hispanics nonmenthol users, Hispanics menthol users were more likely to smoke more than a pack per day $(\mathrm{OR}=2 ; 95 \%$ CI: $1-4.65, P=0.03)$. 
Table 2 Baseline sociodemographic information for HIV-infected participants by race/ethnicity

\begin{tabular}{lllll}
\hline & Hispanic white & $\begin{array}{l}\text { Non-Hispanic } \\
\text { white }\end{array}$ & $\begin{array}{l}\text { Non-Hispanic } \\
\text { black }\end{array}$ & $\begin{array}{l}\text { P value } \\
\text { Age }\end{array}$ \\
Men & $43.4 \pm 10$ & $47.9 \pm 9$ & $42.6 \pm 9.4$ & 0.1 \\
Women & $63 \%$ & $70 \%$ & $60 \%$ & 0.7 \\
Income $<20,000 / y$ & $37 \%$ & $30 \%$ & $40 \%$ & \\
CD4 cell & $93 \%$ & $80 \%$ & $91 \%$ & 0.8 \\
counts & $276.6 \pm 56$ & $336 \pm 105$ & $278.9 \pm 33$ & \\
Viral load & & & $1,45,278 \pm 49,849$ \\
HAART & $1,31,510 \pm 4 I, 523$ & $2,32,083 \pm 1,53,895$ & $25 \%$ & 0.5 \\
Albumin & $31 \%$ & $20 \%$ & $3.9 \pm 0.2$ & 0.7 \\
\hline
\end{tabular}

Abbreviations: HIV, human immunodeficiency virus; HAART, highly active antiretroviral treatment.

In PLWH, IL-6 levels were higher in smokers in comparison with nonsmokers $(3.6 \pm 0.8$ vs $3.3 \pm 1 \mathrm{log})$. IL-6 levels in culture supernatants differed between African Americans and Hispanics (1,773 \pm 618 vs 2,905.4 $\pm 454 \mathrm{log})$. The interaction term essentially separates African American menthol cigarette smokers from Hispanics and recomputes their risk for being in higher levels of IL-6 production. Smokers were twice as likely to have more than 2,5 log than nonsmokers (95\% CI: $1.1-15, P=0.05)$.

When analyses were stratified by CD4 counts, African Americans with more than 200 CD4 cell counts tended to have higher IL-6 levels than Hispanics $(3,925 \pm 1454$ vs $3,453 \pm 1618 \log , P=0.05)$. However, as illustrated in Figure 2, African Americans with less than 200 CD4 cells who smoked mentholated cigarettes have significantly higher IL-6 values $(4.7 \pm 0.8$ vs $3,453 \pm 1618 \log , P=0.03)$.

\section{Differences on IL-6 according to alcohol consumption}

To extend existing studies in the search for IL-6 modifiers in PLWH, we examined hazardous alcohol use as a potential contributor. This factor proved to be significant with IL-6

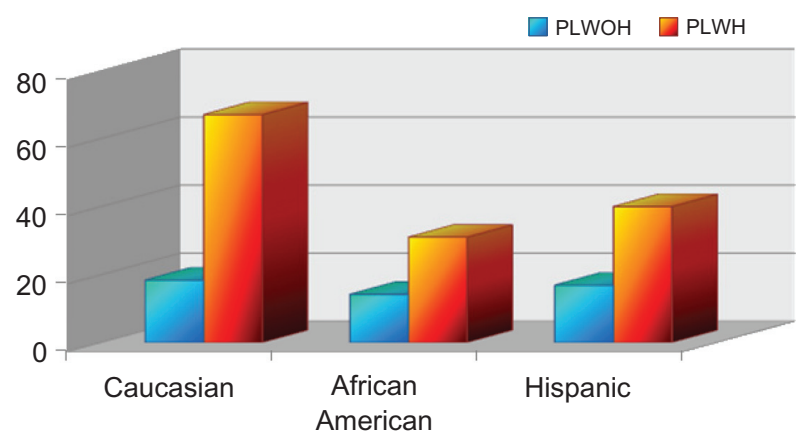

Figure I Prevalence of smoking by HIV status and race/ethnicity.

Notes: Data are prevalence of tobacco by HIV status and race/ethnicity. PLWH had significantly higher rates of tobacco $(31 \%-67 \%)$ than PLWOH $(14 \%-18 \%, P=0.00 I)$. Abbreviations: HIV, human immunodeficiency virus; $\mathrm{PLWOH}$, people living without HIV. levels significantly increased in hazardous drinkers compared with nonhazardous drinkers $(3,6 \pm 0.6$ vs $3,1 \pm 1.3$ $\log , P=0.04)$. To assess the potential effects of nutritional parameters in altering IL-6 results, we examined IL-6 interactions with dietary intake, albumin, and BMI, but there was none. Moreover, the observed interaction between IL-6 production and alcohol remained significant after controlling for these potential confounders.

\section{Multivariate regression analyses}

In multivariate logistic regression, smoking mentholated cigarettes, race, and hazardous alcohol use remained independently associated with IL-6 levels more than 75 percentile, after adjusting for gender, HAART, CDC stage of HIV disease, and BMI (Table 3). Of interest, smoking was borderline significant, but smoking mentholated brands were a significant predictor of IL-6 levels.

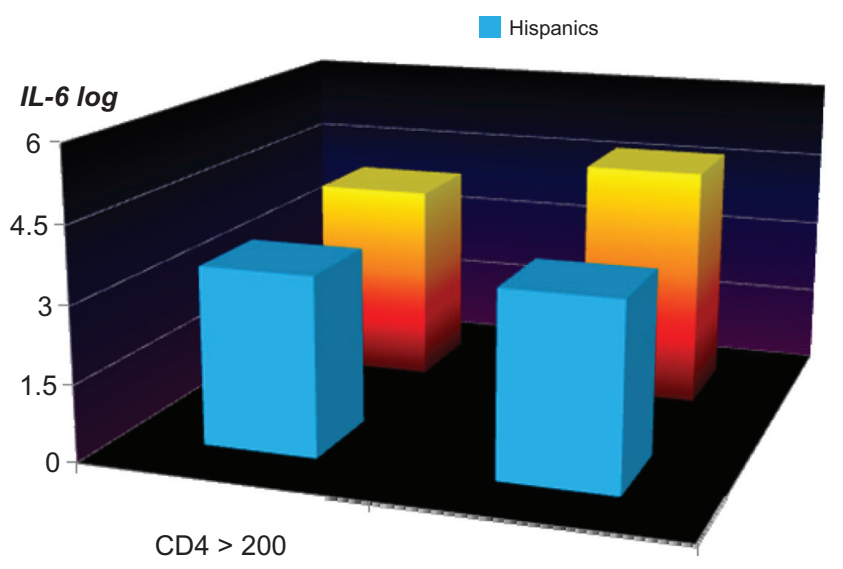

CD4 $<200$

Figure 2 IL- 6 by race and CD4 in PLWH who used mentholated cigarettes. Notes: Data represent the logarithm of IL6 levels in the supernatant of stimulated PBMC and evident differences in the production between Hispanics and African Americans, particularly those with less than 200 CD4 cell counts $(P=0.03)$. Abbreviations: IL-6, interleukin-6; PLWH, people living with HIV; PBMC, peripheral blood mononuclear cells. 
Table 3 Multivariate analyses for elevated IL-6 values

\begin{tabular}{llll}
\hline Model & \multicolumn{3}{l}{ Predictors of high IL-6 levels } \\
\cline { 2 - 4 } & Multivariate RR & $\mathbf{9 5 \%} \mathbf{~ C l}$ & P value \\
\hline $\begin{array}{l}\text { Hazardous } \\
\text { liquor use }\end{array}$ & 8.4 & $1.3-25$ & 0.03 \\
$\begin{array}{l}\text { Race/ethnicity } \\
\text { Black versus Hispanic } \\
\text { plus non-Hispanic whites }\end{array}$ & 9.5 & $2.2-40$ & 0.002 \\
$\begin{array}{l}\text { Thrombocytopenia } \\
\begin{array}{l}\text { Use of mentholated } \\
\text { cigarettes }\end{array}\end{array}$ & 4.6 & & \\
\hline
\end{tabular}

Notes: RR represents the final logistic regression model predicting having IL-6 values more or less than $75 \%$ percentile. Significance was set at 0.05 . Model statistics computed include adjusted $\mathrm{OR}, 95 \% \mathrm{Cl}$, and their corresponding $P$ values. All variables were set as dichotomous variables.

Abbreviations: IL-6, interleukin-6; Cl, confidence interval; OR, odds ratio.

\section{Discussion}

To date, there are no published studies examining the potential effects of mentholated cigarette smoking in relation to ethnic differences and HIV infection. Our findings provide information that menthol, an additive found in many American cigarette brands, is a modifiable risk for abnormal IL-6 production. Although a previous HIV-national study failed to analyze the effect of smoking on IL-6 levels, ${ }^{11}$ our data suggest that the increased use of mentholated cigarettes among African Americans and Hispanics may be enhancing proinflammatory responses. These findings have important public health implications when considering that approximately two-thirds of PLWH in the United States are either African Americans or Hispanics. They also highlight the importance of carefully analyzing racial/ethnic differences in PLWH and obtaining detailed behavioral information.

It has been repeatedly reported in the literature that minority populations, particularly African Americans, are more vulnerable than Caucasians to several tobacco-related diseases. ${ }^{25-27}$ When infected with HIV, a recent report from Flexible Initial Retrovirus Suppressive Therapies (FIRST) concluded that African Americans and Hispanics have lower health outcomes, lower rates of viral suppression, and less $\mathrm{CD}^{+}{ }^{+}$cell count. ${ }^{27}$ We examined socioeconomic, behavioral, and racial differences as potentially confounding factors related to the observed differences. In agreement with previous studies in the general population, our data have suggested racial differences on IL-6 levels., ${ }^{4,5,28}$ Consistent with prior reports, differences in IL-6 production were evident between non-Hispanic Caucasians, Hispanics, and African Americans, with African Americans exhibiting the lowest IL-6 levels. ${ }^{29}$ More critically, however, our study extends earlier findings by showing, for the first time, that using mentholated cigarettes may impose additional burdens on the body's regulation of inflammatory response among African Americans and Hispanics living with HIV. These increases in IL-6 parallel the CD4 and viral outcomes in those receiving HAART and, consequently, may help explain the findings from the FIRST multisite trial. ${ }^{27}$ The implications of these results may be important regarding morbidity, particularly, since high IL-6 levels have been associated with cognitive impairment, kidney damage, and cardiovascular diseases. ${ }^{30-32}$ Most alarming, in the Strategies for Management of Anti Retroviral Therapy (SMART) study, is that the IL-6 elevations after HAART initiation were associated with an increased risk of all cause-mortality. ${ }^{33}$ Thus, it is likely that by avoiding smoking, significant reductions of IL-6 can be achieved, enhancing the life expectancy of the populations.

With regards to behavioral factors, our findings indicate that menthol itself may compound the risk of tobacco's proinflammatory effects. Menthol is a cigarette additive that probably increases health risk by enhancing exposure to tobacco smoke toxins. ${ }^{14-16}$ Menthol use predicts heavy smoking, depresses respiratory activity, and increases risk of respiratory infections. ${ }^{6}$ Because there is little data evaluating its potential immune effects, mechanistic studies would seem important for directly assessing possible menthol risks, given that patients with chronic inflammation constitute a major clinical hurdle, due to the threat of disease progression, medical complications, and increased mortality risks. Although data regarding the deleterious effects of menthol have been inconsistent, there have been repeated indications in the literature that ethnic minorities, particularly African Americans, face greater difficulties in achieving smoking cessation if they use mentholated cigarettes. ${ }^{12-15}$ Our data also indicated that hazardous alcohol use may increase this chronic proinflammatory state reinforcing the urgency of preventive strategies tailored to African Americans and Hispanics and aimed at their specific risks.

Finally, in contrast to studies relating health disparities to socioeconomical variables, our findings did not attribute health disparities to sociodemographic unbalances. Similar to our findings in HIV-infected active military personnel and veterans, populations with few barriers to care have also found disparities in outcomes by race/ethnicity. ${ }^{34}$

Our findings may be limited in several ways. A longitudinal study, instead of a case-control, may provide a more precise estimate of true values, and because of the correlative nature of this study, causality cannot be definitely inferred. The strictest association between smoking, particularly mentholated use and IL-6 regulation, and the persistence of the 
relationship after controlling for confounders indicate that they are closely related. However, our findings are limited to patients seen at Jackson Memorial Medical Center, and our power necessarily limited our analyses. Our analyses pertained to Caucasians, Hispanics, and African Americans, so the ability to generalize to other race/ethnic groups is uncertain. Therefore, larger studies, with longer follow-up times, are recommended.

Race/ethnic differences in association with inflammatory markers and diseases have important clinical and public health implications, as well as complexities, in relation to structural health disparities. ${ }^{1-6,11}$ These have been reviewed by Barnes $^{35}$ who emphasizes the value of fully explaining these differences, including the genetic contribution, in reinforcing our priorities on eliminating health disparities. The role of host genomic factors on HIV pathogenesis has long been documented.$^{36}$ Links to persistent ethnic differences and racial disparities have also emerged but remain complex. ${ }^{37}$ Yet, the cumulative evidence of ethnic differences in inflammatory response has been evident and highlights the importance of tailored investigations and preventive interventions, which have been repeatedly emphasized in HIV sociobehavioral and structural prevention research. ${ }^{38}$ As Cohen et al ${ }^{39}$ illustrated, the most surprising and fundamental characteristic of the HIV epidemic have been the persistent heterogeneity of its impact and distribution across populations and regions. Diverse presenters at the CROI 2010 (17th Conference on Retroviruses and Opportunistic Infections) were united in the recognition of this point and the need for combination prevention strategies, which take a comprehensive account of both the biomedical (including genetic) and sociobehavioral dimensions of risks in future research and customized interventions. Our study highlights the importance of incorporating consideration of racial/ethnic differences in specifying the risk behaviors of vulnerable populations. It also reinforces the need for tailored preventive services in reducing modifiable health risks, such as tobacco and alcohol use, to eliminate health disparities among at-risk populations.

\section{Disclosure}

The authors report no conflicts of interest in this work.

\section{References}

1. Liu Y, Berthier-Schaad Y, Fallin MD, et al. IL-6 haplotypes, inflammation, and risk for cardiovascular disease in a multiethnic dialysis cohort. [Erratum appears in J Am Soc Nephrol. 2006;17(11):3264]. J Am Soc Nephrol. 2006;17(3):863-870.

2. Pradhan AD, Manson JE, Rifai N, Buring JE, Ridker PM. C-reactive protein, interleukin 6 , and risk of developing type 2 diabetes mellitus. JAMA. 2001;286:327-334.
3. Bermudez EA, Rifai N, Buring J, Manson JE, Ridker PM. Interrelationships among circulating interleukin-6, C-reactive protein, and traditional cardiovascular risk factors in women. Arterioscler Thromb Vasc Biol. 2002;22:1668-1673.

4. Enewold L, Mechanic LE, Bowman ED, et al. Serum concentrations of cytokines and lung cancer survival in African Americans and Caucasians. Cancer Epidemiol Biomarkers Prev. 2009;18(1): 215-222.

5. Blake GJ, Ridker PM. Inflammatory bio-markers and cardiovascular risk prediction. J Intern Med. 2002;252(4):283-294.

6. Lowe GD. The relationship between infection, inflammation, and cardiovascular disease: an overview. Ann Periodontol. 2001;6(1):1-8.

7. Saijo Y, Yoshioka E, Fukui T, et al. Effects of the interaction between interleukin-6-634C/G polymorphism and smoking on serum C-reactive protein concentrations. Hypertens Res. 2007;30:593-599.

8. Friedlander Y, Kark JD, Sinnereich R, Tracy RP, Siscovick DS Fibrinogen and CRP in Israeli families, genetic and environmental sources of concentrations and longitudinal changes. Atherosclerosis. 2006;189:167-177.

9. Karakas M, Baumert J, Greven S, Rückerl R, Peters A, Koenig W. Reproducibility in serial C-reactive protein and interleukin-6 measurements in post-myocardial infarction patients: results from the AIRGENE study. Clin Chem. 2010;56(5):861-864.

10. Sunyer J, Forastiere F, Pekkanen J, et al; AIRGENE Study Group. Interaction between smoking and the interleukin- 6 gene affects systemic levels of inflammatory biomarkers. Nicotine Tob Res. 2009;11(11):1347-1353.

11. Neuhaus J, Jacobs D, Baker J, et al. Markers of inflammation, coagulation, and renal function are elevated in adults with HIV infection. J Infect Dis. 2010;201:1788-1795.

12. Okuyemi KS, Ebersole-Robinson M, Nazir N, Ahluwalia JS. AfricanAmerican menthol and nonmenthol smokers: differences in smoking and cessation experiences. J Natl Med Assoc. 2004;96(9):1208-1211.

13. Gandhi KK, Foulds J, Steinberg MB, Lu SE, Williams JM. Lower quit rates among African American and Latino menthol cigarette smokers at a tobacco treatment clinic. Int J Clin Pract. 2009;63(3): 360-367.

14. Gundersen DA, Delnevo CD, Wackowski O. Exploring the relationship between race/ethnicity, menthol smoking, and cessation, in a nationally representative sample of adults. Prev Med. 2009;49(6):553-557. Epub 2009 Oct 19.

15. Unger JB, Allen B Jr, Leonard E, Wenten M, Cruz TB. Menthol and non-menthol cigarette use among Black smokers in Southern California. Nicotine Tob Res. 2010;12(4):398-407.

16. Giovino GA, Sidney S, Gfroerer JC, et al. Epidemiology of menthol cigarette use. Nicotine Tob Res. 2004;6 Suppl 1:S67-S81.

17. Abolhassani M, Guais A, Chaumet-Riffaud P, Sasco AJ, Schwartz L. Carbon dioxide inhalation causes pulmonary inflammation. Am J Physiol Lung Cell Mol Physiol. 2009;296(4):L657-L665. Epub 2009 Jan 9.

18. Moreira Guimarães MM, Bartolomeu Greco D, Ingles Garces AH, de Oliveira AR Jr, Bastos Fóscolo R, de Campos Machado LJ. Coronary heart disease risk assessment in HIV-infected patients: a comparison of Framingham, PROCAM, and SCORE risk assessment functions. Int $J$ Clin Pract. 2010;64(6):739-745.

19. Szczech LA. Monitoring HIV patients' kidney function in clinical practice. What is known about kidney disease in other clinical contexts can help guide HIV care providers in monitoring kidney function in their patients. AIDS Clin Care. 2009;21(11):92-94.

20. Vance DE, Mugavero M, Willig J, Raper JL, Saag MS. Aging with HIV: a cross-sectional study of comorbidity prevalence and clinical characteristics across decades of life. JAssoc Nurses AIDS Care. 2010 May 13. [Epub ahead of print].

21. Panel on Antiretroviral Guidelines for Adults and Adolescents. Guidelines for the use of antiretroviral agents in HIV-1-infected adults and adolescents. Department of Health and Human Services. 2008 Nov 3. Available at: http://www.fda.gov/ForConsumers/ByAudience/ ForPatientAdvocates/HIVandAIDSActivities/ucm 121604.htm 
22. Babor TF, Higgins-Biddle JC, Saunders JB, Monteiro MG. AUDIT. Available at: http://whqlibdoc.who.int/hq/2001/WHO_MSD_ MSB_01.6a.pdf

23. Thomas McLellan, Deni Carise, Thomas H Coyne. Addiction Severity Index. 5th ed. Available at: http://www.densonline.org/DENSASI.pdf

24. NIAAA and American Association guidelines. Available at http:// rethinkingdrinking.niaaa.nih.gov/IsYourDrinkingPatternRisky/WhatsAtRiskOrHeavyDrinking.asp>. Accessed: June 20, 2010.

25. Kunze M, Groman E, Kunze U. Tobacco consumption and tobaccorelated diseases. J Mens Health. 2004;1(1):83-87.

26. Hutchins S, Fiscella K, Levine RS, Ompad DC, McDonald M. Protection of racial/ethnic minority populations during an influenza pandemic. Am J Public Health. 2009;99(S2):S261-S270.

27. Giordano TP, Bartsch G, Zhang Y, et al. Disparities in outcomes for African American and Latino subjects in the Flexible Initial Retrovirus Suppressive Therapies (FIRST) trial. AIDS Patient Care STDS. 2010; 24(5):287-295.

28. Velez DR, Menon R, Thorsen P, et al. Ethnic differences in interleukin 6 (IL-6) and IL6 receptor genes in spontaneous preterm birth and effects on amniotic fluid protein levels. Ann Hum Genet. 2007; 71(Pt 5):586-600.

29. Allison M, Criqui M, McClelland R, et al. The Effect of novel cardiovascular risk factors on the ethnic-specific odds for peripheral arterial disease in the Multi-Ethnic Study of Atherosclerosis (MESA). J Am Coll Cardiol. 2006;48(6):1190-1197.

30. Narkiewicz K, van de Borne PJ, Hausberg M, et al. Cigarette smoking increases sympathetic outflow in humans. Circulation. 1998;98(6): $528-534$.
31. Stengel B, Couchoud C, Cénée S, Hémon D. Age, blood pressure, and smoking effects on chronic renal failure in primary glomerular nephropathies. Kidney Int. 2000;57(6):2519-2526.

32. Wesson DE. The relationship of cigarette smoking to end-stage renal disease. Semin Nephrol. 2003;23(3):317-322.

33. Kuller LH, Tracy R, Belloso W, Wit SD, Drummond F, et al. (2008) Inflammatory and Coagulation Biomarkers and Mortality in Patients with HIV Infection. PLoS Med 5(10): e203. doi:10.1371/journal. pmed.0050203

34. Jha AK, Shlipak MG, Hosmer W, Frances CD, Browner WS. Racial differences in mortality among men hospitalized in the veterans affairs health care system. JAMA. 2001;285:297-303.

35. Barnes KC. Genetic determinants and ethnic disparities in sepsisassociated acute lung injury. Proc Am Thorac Soc. 2005;2(3): 195-201.

36. Fellay J. Host genome influences on HIV-1 disease. Antivir Ther. 2009; 14(6):731-738.

37. Ness R, Haggerty C, Harger G, Ferrell R. Differential distribution of allelic variants in cytokine genes among African Americans and White Americans. Am J Epidemiol. 2004;160(11):1033-1038.

38. Coates TJ, Richter L, Caceres C. Behavioural strategies to reduce HIV transmission: how to make them work better. Lancet. 2008;372(9639): 669-684.

39. Cohen M, Hellmann N, Levy J, DeCock K, Lange J. The spread, treatment, and prevention of HIV-1: evolution of a global pandemic. J Clin Invest. 2008;118(4):1244-1254.

\section{Publish your work in this journal}

The International Journal of Interferon, Cytokine and Mediator Research is an international, peer-reviewed, open-access, online journal. The focus of the journal is to publish original research, reports, editorials, reviews and commentaries on all aspects of interferon, cytokine and mediators of inflammation from labora- tory science to therapeutic indications and clinical studies. The manuscript management system is completely online and includes a very quick and fair peer-review system, which is all easy to use. Visit http://www.dovepress.com/testimonials.php to read real quotes from published authors. 